\title{
Killer Factor in Wine Yeasts and its Effect on Fermentation
}

\author{
H.G. Tredoux, R.P. Tracey and A. Tromp \\ Viticultural and Oenological Research Institute, Private Bag X5026, 7600, Stellenbosch, Republic of South Africa.
}

Submitted for publication: July 1986

Accepted for publication: September 1986

Keywords: Killer factor, yeast strain, fermentation, wine.

\begin{abstract}
The occurrence of killer factor amongst yeast strains in the Viticultural and Oenological Research Institute (VORI) yeast collection was studied. From a total of 96 strains, 85 were Saccharomyces cerevisiae of which 7 strains were killer, 9 neutral and 69 sensitive. These included some imported strains. On agar, no killer action was detected at wine pH. In fermentation studies using four grape cultivars, it was shown that where the killer yeast population was less than approximately $2,5 \%$ fermentation was not affected. At higher levels the killer yeast, in some instances, took over and completed fermentation, but the total fermentation time was never longer than that of the killer strain on its own. It was concluded that the use of a yeast strain should not hinge on its killer character but rather on its oenological characteristics.
\end{abstract}

Killer activity in Saccharomyces cerevisiae was first described by Bevan \& Makower (1963). Four phenotypes (or groups) have been shown to exist namely killer (K), sensitive (S), neutral (N) and killer-sensitive (K-S) strains (Bevan \& Makower, 1963; Woods, Ross \& Hendry, 1974). The K-S strains form killer factor but are also sensitive to other killer yeasts.

Killer activity has been reported for various yeast genera but is notably found in the genus Saccharomyces. Other genera that show killer activity are Pichia, Candida, Hansenula, Kluyveromyces, Debaryomyces and Cryptococcus (Philliskirk \& Young, 1975; Stumm et al., 1977; Rosini, 1983). Killer strains of Sacch. cerevisiae have been found among brewing yeasts (Maule \& Thomas, 1973), saké yeasts (Imamura, Kawamoto \& Takoaka, 1974) as well as wine yeasts (Barre, 1984).

In a study covering all the major wine-producing areas of France, Cuinier \& Gros (1983) found that the occurrence of killer yeasts in the wine at the end of spontaneous alcoholic fermentation varied between $0 \%$ and $100 \%$. Samples from the Touraine area contained no killer yeasts, whilst those from the Gard and Beaujolais areas consisted only of killer yeasts. Spontaneous fermentations studied in the Piedmont area of Italy were carried out by sensitive strains of Saccharomyces (Ciolfi, 1985). Barre (1984) states that where spontaneous wine fermentations occur, the initial killer yeast population must be greater than $2 \%$ of the total population for the killer yeast to be the dominant strain at the end of alcoholic fermentation. Cuinier \& Gros (1983) noted that no difference was found in the fermentations of K or S strains, whilst Barre (1984) states that should one wish to obtain a fermentation with a pure strain, it is possible to select clones resistant to specific killer yeasts by a process of enrichment. Hammond \& Eckersley (1984) found that in taste tests beers produced by killer brewing strains could not be distinguished from control beers. In addition to producing good beers, they found that genetically manipulated yeasts killed a range of contaminant yeasts and were themselves immune to the action of killer yeasts.

A recent tendency in the wine and beer industries is to construct yeasts with killer activity (Hara, Iimura \& Otsuka, 1980; Young, 1981; Seki, Choi \& Ryu, 1985). The reason given, noted particularly by Hara et al.
(1980) and Seki et al. (1985), is that should a fermentation be inoculated with killer yeasts, it is most likely that the killer yeast will dominate and complete the fermentation.

It should be remembered, that in countries such as France, spontaneous fermentations make up the greatest percentage of all wine fermentations. However, in countries such as South Africa and Australia, the majority of wine fermentations are carried out by using active dried wine yeasts (ADWY) (Rankine, 1978). This results in a totally different approach to the role of killer strains in wine fermentations. A prime condition for success with ADWY is to ensure that the introduced yeast cells are present in sufficient numbers to compete with the natural flora and thus be responsible for the wine fermentations (Anon., 1984). It is further noted that yeasts possessing a killer factor should be considered when making this choice. It was concluded that killer strains easily dominate and control the fermentation environment and that killer activity should be one of the characteristics considered when evaluating wine yeasts. Characteristics such as alcohol tolerance, $\mathrm{H}_{2} \mathrm{~S}$ production, volatile acid production and fermentation rate are, however, equally important. In South Africa a number of local and imported ADWY strains are used in the wine industry. Of the four locally produced ADWY strains, it has been shown by Shimizu et al. (1985a) that Sacch. cerevisiae strains WE 14 and WE 372 (VORI collection) both possess killer activity. It was further shown by these authors that these two strains are of the $\mathrm{K}_{2}$ killer type (Shimizu et al., 1985b).

Stumm et al. (1977) observed that maximum killer

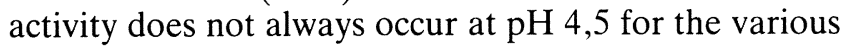
genera studied. Rogers \& Bevan (1978) found that the optimum $\mathrm{pH}$ for killer activity for Sacch. cerevisiae varied between $\mathrm{pH} 4,2$ and 4,7 whilst for strains of various genera, Pfeiffer \& Radler (1984) found the optimum $\mathrm{pH}$ for killer activity to be between $\mathrm{pH} 4,2$ and 4,4 for $\mathrm{K}_{2}$ types. The $\mathrm{K}_{1}$ strain studied by them had an optimum $\mathrm{pH}$ of 4,7 while the $\mathrm{K}_{1}$ strain studied by Shimizu et al. (1985b) had an optimum $\mathrm{pH}$ of 4,9.

The purpose of this study was to determine the occurrence of killer activity amongst wine yeast strains, the effect of temperature and $\mathrm{pH}$ on killer action and the role of killer yeasts in wine fermentations. 


\section{MATERIALS AND METHODS}

\section{Microbiological Studies}

Yeast strains: Ninety-six yeast strains from the VORI culture collection, including 85 Sacch. cerevisiae strains, one strain each of the genera Toroluspora, Hansenula, Debaryomyces and Pichia, two strains each of the genera Kluyveromyces and Schizosaccharomyces and three Candida strains were included in this study. NCYC 738 (killer strain) and NCYC 1006 (sensitive strain) were obtained from the National Collection of Yeast Cultures (England) and strains WE 14 and WE 372 (killer strains, Shimizu et al., 1985a; 1985b) and WE 500 (sensitive strain, Shimizu et al., 1985b) obtained from the VORI culture collection were all Sacch. cerevisiae strains and were used as reference strains.

Assay for killer and sensitive characters: This was done using the method of Rosini (1983) which was modified by changing the $\mathrm{pH}$ of the medium to 4,8 (Shimizu et al., 1985a) and incubating the cultures for 48 hours at $25^{\circ} \mathrm{C}$. Yeasts which killed both NCYC 1006 and WE 500 as shown by zones of inhibition, were designated as killer strains. Strains NCYC 738, WE 14 and WE 372 were streaked onto the solidified agar medium containing the yeast to be tested. The formation of an inhibition zone was used to designate sensitive yeast strains. Strains which showed no reaction were designated as neutral. The VORI culture collection was tested as described above. Additionally, fourteen Sacch. cerevisiae yeast strains, including those currently in use in the South African wine industry were selected from the culture collection and tested in a matrix against one another (strains $\mathrm{N} 95, \mathrm{~N} 96, \mathrm{~N} 97, \mathrm{~N}$ 99, WE 14, WE 365, WE 372, WE 406, WE 407, WE 432, WE 452, WE 462, WE 466 and WE 500 of the VORI collection).

The effect of $\mathrm{pH}$ and temperature on killer action: Killer "action" is defined as the combined effect of killer yeast growth, killer toxin production and activity of the killer toxin. Killer action is thus a practical criterion which shows the effect of killer yeasts on sensitive strains and finds expression in the diameter of inhibition zones. Malt extract broth (MEB) was set at $\mathrm{pH}$ 3,$0 ; 3,3 ; 3,5 ; 3,7 ; 3,9 ; 4,2 ; 4,5$ and 4,8 with $10 \mathrm{~N} \mathrm{HC1}$. To avoid hydrolysis of the agar, the MEB and agar $(2 \%$ $\mathrm{m} / \mathrm{v}$ ) were sterilised separately and subsequently cooled to $45^{\circ} \mathrm{C}$, mixed, inoculated with a suspension of WE 500 containing $4,2 \times 10^{6}$ cells $/ \mathrm{m} l$ and poured into Petri dishes. Pinpoint inoculations were made into the agar using killer strains WE 14 and WE 372 as well as WE 500 as control strain. Plates were incubated at $15^{\circ} \mathrm{C}$ and $25^{\circ} \mathrm{C}$ and examined after 72 hours for inhibition zones. Where inhibition zones occurred, their diameters were measured.

\section{Fermentation Studies}

Four grape musts were employed in fermentations with mixed cultures of killer and sensitive strains to determine the effect of the latter on rate of fermentation, total fermentation time (TFT) and wine composition.

Grape Musts: The grapes were crushed, destemmed and the free-run juice separated from the skins. After addition of $30 \mathrm{~g} / \mathrm{h} l$ of bentonite the juice was settled overnight at $0^{\circ} \mathrm{C}$ and the clear juice racked from its lees. Except for the Chenin blanc juice, all the musts were sulphited to $80 \mathrm{mg} / l \mathrm{SO}_{2}$ (total) as is customary in practice. The four grape musts used had the following analyses:

$\begin{array}{llll}\text { Cultivar } & \begin{array}{l}\text { Sugar } \\ \left({ }^{\circ} \mathrm{B}\right)\end{array} & \begin{array}{l}\text { Total } \\ \text { acidity } \\ (\mathrm{g} / l)\end{array} & \mathrm{pH} \\ \text { Chenin blanc } & 20,8 & 8,3 & 3,18 \\ \text { Gewürztraminer } & 22,1 & 5,6 & 3,47 \\ \text { Riesling } & 19,0 & 8,4 & 3,10 \\ \text { Vital } & 23,9 & 6,0 & 3,35\end{array}$

Yeast strains and culture preparation: Two killer and two sensitive strains from the VORI collection were used. All four strains are Sacch. cerevisiae and are those mainly employed by the South African wine industry as ADWY.

$\begin{array}{lll}\text { Strains } & \text { Killer } & \text { Origin and use } \\ \text { status }\end{array}$

WE 500 sensitive Imported strain selected for

WE 432 sensitive Danish strain 228 used for production of distilling wine, fast fermentor.

WE 14 killer

Both strains selected from South African wines for production of quality wines, slow fermentors.

Starter culture preparation was done directly from agar slants of the VORI collection and propagated stepwise in sterilised Chenin blanc must. The last propagation step was done in a glass vessel fitted with a fermentation lock to simulate the virtual anaerobic conditions encountered in practice during starter culture preparation. Fermentation was carried out at $15^{\circ} \mathrm{C}$ and the cultures were ready after approximately $5-10^{\circ} \mathrm{B}$ had fermented. Before use the live cell counts of all starter cultures were done, using malt extract agar.

Fermentations: All fermentations were carried out in $750 \mathrm{~m} l$ bottles fitted with fermentation locks. All bottles were rinsed with distilled water and drained prior to use. Two experiments were made.

\section{Experiment 1:}

The Chenin blanc and Gewürztraminer musts were subdivided into 16 aliquots of $500 \mathrm{~m} l$ each. By adding decreasing volumes of WE 500, and increasing volumes of WE 14 starter culture, each aliquot was inoculated with a total volume of $15 \mathrm{~m} l$ to yield the following treatments in duplicate:

$\begin{array}{lllllllll}\text { treatment } & 1 & 2 & 3 & 4 & 5 & 6 & 7 & 8\end{array}$

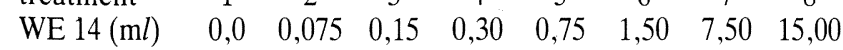

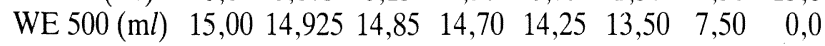

In this way increasing amounts of the killer strain (WE 14) were inoculated together with the sensitive strain (WE 500) with the $15 \mathrm{~m} l$ inoculations of both WE 14 and WE 500 serving as control treatments.

\section{Experiment 2:}

Exactly the same procedure as above was followed to inoculate both Riesling and Vital musts with the killer strain/sensitive strain combinations WE 372/WE 500 and WE 14/WE 432 to obtain the same treatments as tabulated under experiment 1. 
All fermentations were carried out at $15^{\circ} \mathrm{C}$. Fermentation curves were established by plotting daily mass loss due to $\mathrm{CO}_{2}$ evolution. At the point when there was no furhter change in mass, (less than $0,1 \mathrm{~g}$ per $500 \mathrm{ml}$ mass loss per day) TFT was noted and the wines decanted for analysis of alcohol, sugar, total and volatile acidity and free and total $\mathrm{SO}_{2}$ by standard VORI methods. One millilitre of the yeast sediment of each wine was suspended in $5 \mathrm{ml}$ physiological salt solution.

Of this, $0,1 \mathrm{~m} l$ was plated and tested for killer activity or sensitivity according to the method described under the microbiological studies. An analysis of variance was performed on the data and use was also made of the Scott-Knott method of grouping means (Scott \& Knott, 1974).

\section{RESULTS AND DISCUSSION \\ Microbiological Studies}

Killer and sensitive characters: The results obtained with the 96 strains tested are given in Table 1 and indicate that a low incidence of killer activity is found in the genus Saccharomyces. Similar results were obtained with other culture collections by Philliskirk \& Young (1975) and Rosini (1983). Seven of the 85 Sacch. cerevesiae strains that were sensitive to NCYC 738 were found to be not sensitive to strains WE 14 and WE 372 (data not shown). This is of particular interest as all three strains are killers of the $\mathrm{K}_{2}$ type.

\section{TABLE 1}

The occurrence of killer character in yeasts in the VORI culture collection obtained with Sacch. cerevisiae strains NCYC 738 and NCYC 1006.

\begin{tabular}{|l|c|c|c|c|c|}
\hline Species & $\begin{array}{c}\text { No. of } \\
\text { strains } \\
\text { tested }\end{array}$ & $\mathrm{K}^{*}$ & $\mathrm{~S}$ & $\mathrm{~N}$ & $\mathrm{~K}-\mathrm{S}$ \\
\hline Saccharomyces cerevisiae & 85 & 6 & 69 & 9 & 1 \\
Torulaspora delbrueckii & 1 & & & 1 & \\
Kluyveromyces thermotolerans & 2 & & & 2 & \\
Schizosaccharomyces pombé & 2 & & & 2 & \\
Hansenula anomala & 1 & & & 1 & \\
Debaryomyces hansenii & 1 & & & 1 & \\
Candida stellata & 1 & & & 1 & \\
C. inconspicua & 1 & & & 1 & \\
C. tropicalis & 1 & & 1 & & \\
Pichia guilliermondii & 1 & & 1 & & \\
Total & 96 & 6 & 71 & 18 & 1 \\
\hline
\end{tabular}

${ }^{*} \mathrm{~K}=$ Killer

$\mathrm{S}=$ Sensitive

$\mathrm{N}=$ Neutral

$\mathrm{K}-\mathrm{S}=$ Killer-Sensitive

Of the 14 strains sutdied in a matrix, five were found to be killer strains (WE 14, WE 365, WE 372, N 95 and $\mathrm{N}$ 96) and nine strains to be sensitive (WE 406, WE 407, WE 432, WE 452, WE 462, WE 466, WE 500, N 97 and $N$ 99). Of these strains, WE 14 and WE 372 are produced locally and N 95 and N 96 imported killer strains commercially used in the South African wine industry. On the other hand WE 500 (local strain), N 97 and $\mathrm{N} 99$ (imported strains) are sensitive strains also in use in the S.A. wine industry. It is proposed (Anon., 1984) that wine yeasts possessing the killer character should be considered for wine making as these strains can compete actively against the natural flora and thus control and dominate the wine fermentation. However, should this be the major consideration when selecting wine yeasts, the selection would be limited due to the low incidence of killer yeasts in culture collections. Other factors should also be taken into account as stated by Anon. (19084).

Effect of temperature and $\mathrm{pH}$ on killer action: As expected no inhibition zones were formed by WE 500. Diameters of the inhibition zones for strains WE 14 and WE 372 are given in Table 2 . At both $15^{\circ} \mathrm{C}$ and $25^{\circ} \mathrm{C}$ no killer action was detected for strains WE 14 and WE 372 at $\mathrm{pH} \mathrm{3,0}$ to $\mathrm{pH} \mathrm{3,7}$ whilst at $15^{\circ} \mathrm{C}$ WE 14 showed no killer action at $\mathrm{pH} 3,9$. The zone diameters for WE 14 increased with an increase in $\mathrm{pH}$ between 4,2 and 4,8 and slight differences were found between $15^{\circ} \mathrm{C}$ and $25^{\circ} \mathrm{C}$. Strain WE 372 also showed an increase in zone diameters with and increase in $\mathrm{pH}$ at $15^{\circ} \mathrm{C}$, with the zone diameters at $15^{\circ} \mathrm{C}$ larger than those at $25^{\circ} \mathrm{C}$. At $25^{\circ} \mathrm{C}$, however, the zone diameters at $\mathrm{pH} \mathrm{4,2}$ and 4,5 were similar and both larger than those obtained at $\mathrm{pH}$ 3,9 and 4,8 . The optimum $\mathrm{pH}$ of WE 372 is thus between 4,2 and 4,5 at $25^{\circ} \mathrm{C}$. For this strain at $15^{\circ} \mathrm{C}$, as well as for WE 14 at both temperatures, the optimum $\mathrm{pH}$ for killer action is either at $\mathrm{pH} 4,8$ or above.

\section{TABLE 2}

Inhibition zone diameters (in $\mathrm{mm}$ ) obtained for Sacch. cerevisiae killer strains WE 14 and WE 372 at $15^{\circ} \mathrm{C}$ and $25^{\circ} \mathrm{C}$. (WE 500 employed as sensitive strain.)

\begin{tabular}{|c|c|c|c|c|}
\hline $\mathrm{pH}$ & \multicolumn{4}{|c|}{ Strain } \\
\hline & \multicolumn{2}{|c|}{ WE 14} & \multicolumn{2}{c|}{ WE 372 } \\
& $15^{\circ} \mathrm{C}$ & $25^{\circ} \mathrm{C}$ & \multicolumn{2}{c|}{$15^{\circ} \mathrm{C}$} \\
\hline 3,7 & 0 & 0 & 0 & 0 \\
3,9 & 0 & 2,5 & 3,5 & 3,0 \\
4,2 & 3,5 & 3,5 & 5,5 & 4,9 \\
4,5 & 4,0 & 4,2 & 6,9 & 4,8 \\
4,8 & 5,5 & 4,5 & 8,5 & 4,5 \\
\hline
\end{tabular}

\section{Fermentation Studies}

Live cell counts: Taking into account the live cell counts of the different starter cultures used in this study, the relative percentages of the different killer/ sensitive strain combinations recalculates to the figures in Table 3. From Table 3 it can be seen that the lowest and highest live cell counts encountered were $6,1 \mathrm{x}$ $10^{7} / \mathrm{m} l$ and $19,0 \times 10^{7} / \mathrm{m}$ respectively. At an inoculation of $3 \%(15 \mathrm{~m} l$ starter culture added to $500 \mathrm{ml}$ must $)$ the amount of yeast cells introduced into the musts were between $1,8 \times 10^{6} / \mathrm{m} l$ and $5,7 \times 10^{6} / \mathrm{m} l$. This corresponds well with the 1 to $5 \times 10^{6}$ cells per millilitre recommended universally.

\section{Fermentations:}

\section{Experiment 1:}

Results are shown in Figures 1 (A \& B) and 2. For both Chenin blanc and Gewürztraminer it is evident that the killer strain, WE 14 , is a slower fermentor than WE 500 (Fig. 1). This is an inherent characteristic of both strains (Tromp, 1984). None of the Gewürztraminer wines fermented to dryness and fermentations were terminated at 52 days although mass loss still occurred (Fig. 2). No differences in TFT could therefore be noted in this case and there were no significant differences between residual sugar concentrations (data not 

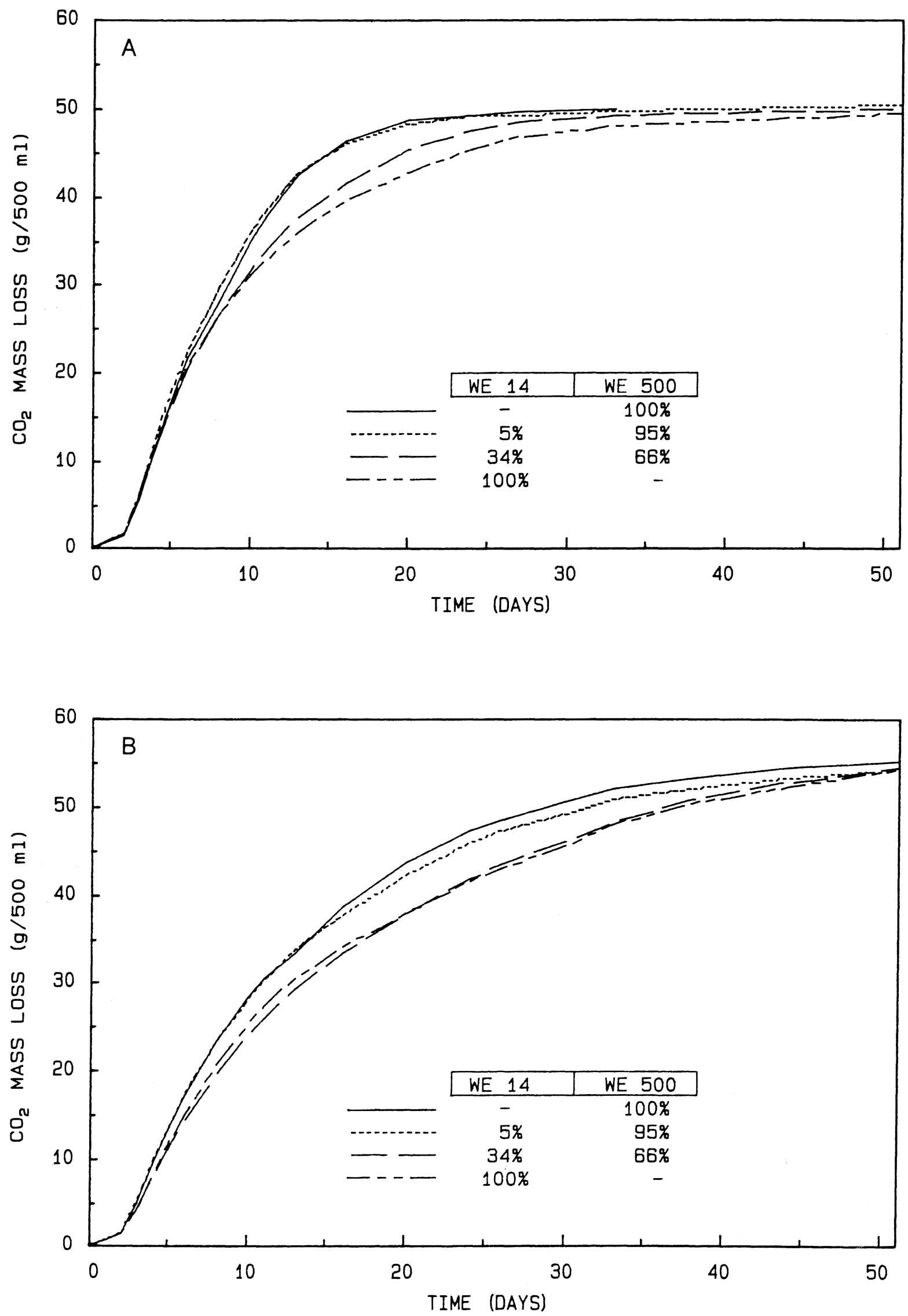

FIG. 1

Fermentation curves obtained in Chenin blanc (A) and Gewürztraminer (B) musts inoculated with varying concentrations of yeast strains WE 14 and WE 500 (VORI collection) at $15^{\circ} \mathrm{C}$. 
TABLE 3

Live cell counts and the relative percentages of yeast strain combinations applied as treatments on Chenin blanc and Gewürztraminer (Exp. 1) and Riesling and Vital (Exp. 2) musts.

\begin{tabular}{|c|c|c|c|c|c|c|c|c|c|c|}
\hline \multirow{2}{*}{ Experiment } & \multirow{2}{*}{$\begin{array}{l}\text { Yeast } \\
\text { strain }\end{array}$} & \multirow{2}{*}{$\begin{array}{l}\text { Live cell } \\
\text { count } \\
\times 10^{7} / \mathrm{m} l\end{array}$} & \multicolumn{8}{|c|}{ Treatments* } \\
\hline & & & 1 & 2 & 3 & 4 & 5 & 6 & 7 & 8 \\
\hline 1 & $\begin{array}{l}\text { WE } 14 \\
\text { WE } 500\end{array}$ & $\begin{array}{r}6,1 \\
12,0\end{array}$ & $\begin{array}{r}0 \\
100\end{array}$ & $\begin{array}{r}0,25 \\
99,75\end{array}$ & $\begin{array}{r}0,5 \\
99,5\end{array}$ & $\begin{array}{r}1 \\
99 \\
\end{array}$ & $\begin{array}{r}2,5 \\
97,5\end{array}$ & $\begin{array}{r}5 \\
95 \\
\end{array}$ & $\begin{array}{l}34 \\
66 \\
\end{array}$ & $\begin{array}{r}100 \\
0 \\
\end{array}$ \\
\hline 2 & $\begin{array}{l}\text { WE } 14 \\
\text { WE } 432 \\
\text { WE } 372 \\
\text { WE } 500\end{array}$ & $\begin{array}{r}9,0 \\
19,0 \\
7,1 \\
11,7\end{array}$ & $\begin{array}{r}0 \\
100 \\
0 \\
100\end{array}$ & $\begin{array}{c}0,25 \\
99,75 \\
0,3 \\
99,7\end{array}$ & $\begin{array}{r}0,5 \\
99,5 \\
0,6 \\
99,4\end{array}$ & $\begin{array}{c}1 \\
99 \\
1,2 \\
98,8\end{array}$ & $\begin{array}{c}2,5 \\
97,5 \\
3 \\
97\end{array}$ & $\begin{array}{r}5 \\
95 \\
6 \\
94\end{array}$ & $\begin{array}{l}32 \\
68 \\
38 \\
62\end{array}$ & $\begin{array}{r}100 \\
0 \\
100 \\
0\end{array}$ \\
\hline
\end{tabular}

* Ratios calculated from live cell counts and inoculum volumes.

shown). Similar results were obtained in other fermentation studies where this Gewürztraminer must was used (data not shown). Killer activity or sensitivity was also tested on the yeasts present in these wines but the results were inconclusive. The Chenin blanc fermentations, on the other hand, showed that WE 500 completed fermentation in under 35 days even if WE 14 was present at 2,5\% (Fig. 2). At these low concentrations the amount of killer toxin secreted by WE 14 was apparently too little to harm WE 500 in any way as the yeasts present after fermentation were still sensitive and thus, in all probability, was strain WE 500. With $5 \%$ or $34 \%$ of the inoculum consisting of killer yeasts, however, fermentations were completed by the killer. From Figure 2 it is also important to note that those fermentations inoculated with killer yeast at a level of $5 \%$ and above did not take longer to complete fermentation than did the killer yeast on its own. When between $0.25 \%$ and $2,5 \%$ WE 14 was present in the inoculum, musts actually fermented to dryness in a shorter time than did musts inoculated with WE 500 alone.

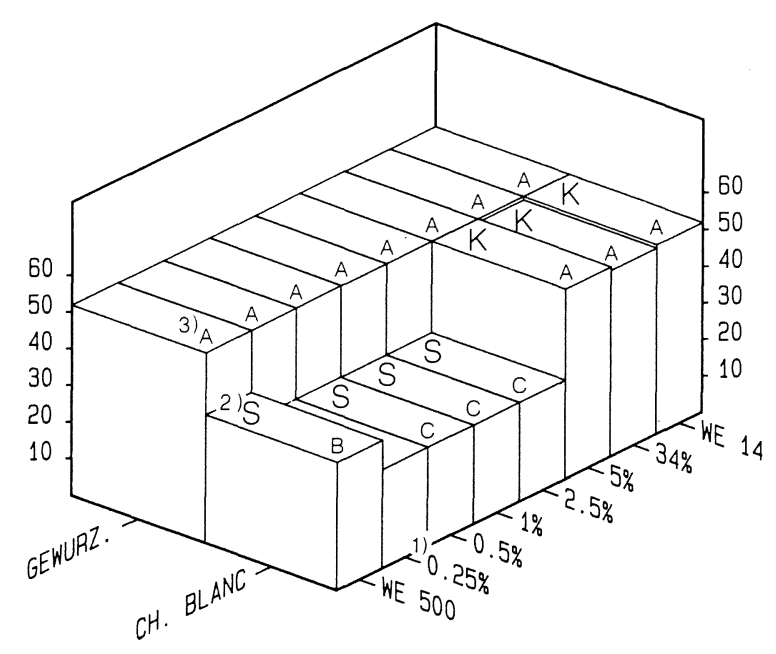

FIG. 2

Total fermentation time (TFT) for Gewürztraminer and Chenin blanc musts inoculated with varying concentrations of yeast strains WE 14 and WE 500 (VORI collection) along with killer status of residual yeasts at the end of fermentation.

1) $0,25 \%$ to $34 \%$ are the ratios of WE 14 to WE 500 in the respective inocula at the start of fermentation.

2) $\mathrm{K}=$ killer and $\mathrm{S}=$ sensitive status of yeasts after fermentation.

3) A,B \& C denote groups which are significantly different (Scott \& Knott, 1974) for each cultivar separately.
From this first experiment it is clear that the killer yeast was unable to take over fermentations if present at $2,5 \%$ or lower at the start of fermentation. This is in accordance with the findings of Barre (1984). The enhancement of the fermentative ability of WE 500 and the consequent shortening of TFT at these low levels cannot be explained.

\section{Experiment 2:}

The effect of the killer strain/sensitive strain combination WE 372/WE 500 on the fermentation of Riesling and Vital musts can be seen in Figures 3(A \& B) and 4. WE 500 completed fermentation within 15 days whilst WE 372 took 47 days. In the presence of up to 3\% killer strain (WE 372), the sensitive strain WE 500 completed fermentations unhindered within 15 days in Vital as shown by the fact that residual yeast was sensitive (S, Fig. 4). In the case of Riesling up to $6 \%$ WE $372 \mathrm{had}$ the same effect but at $38 \%$, TFT was significantly longer although fermentation was completed by WE 500 .

Here, enough killer toxin was apparently produced to affect the performance of WE 500. The same trend is evident in the case of Vital for the 38\% WE 372 addition where the killer strain, however, took over and completed the fermentation. Even in this instance it follows that most of the fermentation must have been done by WE 500 as TFT was significantly, albeit only marginally, increased from 15 days for WE 500 to 19 days where $38 \%$ WE 372 was present.

The fermentation curves of Riesling and Vital musts, where the WE 14/WE 432 combination was applied were very similar for all treatments and are not shown. Differences nevertheless occurred in TFT for Vital and can be seen in Fig. 5. In the case of the Riesling musts TFT values were identical (ca. 20 days) although the killer strain (WE 14) once again took over when comprising $32 \%$ of the inoculum. The killer strain also took over and completed the fermentation at the same concentration in the case of Vital. At 2,5\% and 5\% WE 14 in the initial inoculum, enough toxin was apparently produced to inhibit the fermentation of WE 432. Here TFT was increased from 22 to 27 days. It is once again important to note that this was still not as slow as the killer on its own (TFT $=40$ days, Fig. 5).

Analyses of wines: Except for volatile acidity there were no significant differences between the yeast treatments within a specific cultivar in relation to alcohol, sugar, total acidity and free and total $\mathrm{SO}_{2}$ (data not shown). Differences in the volatile acid (VA) concentrations were probably due to fermentation time rather 

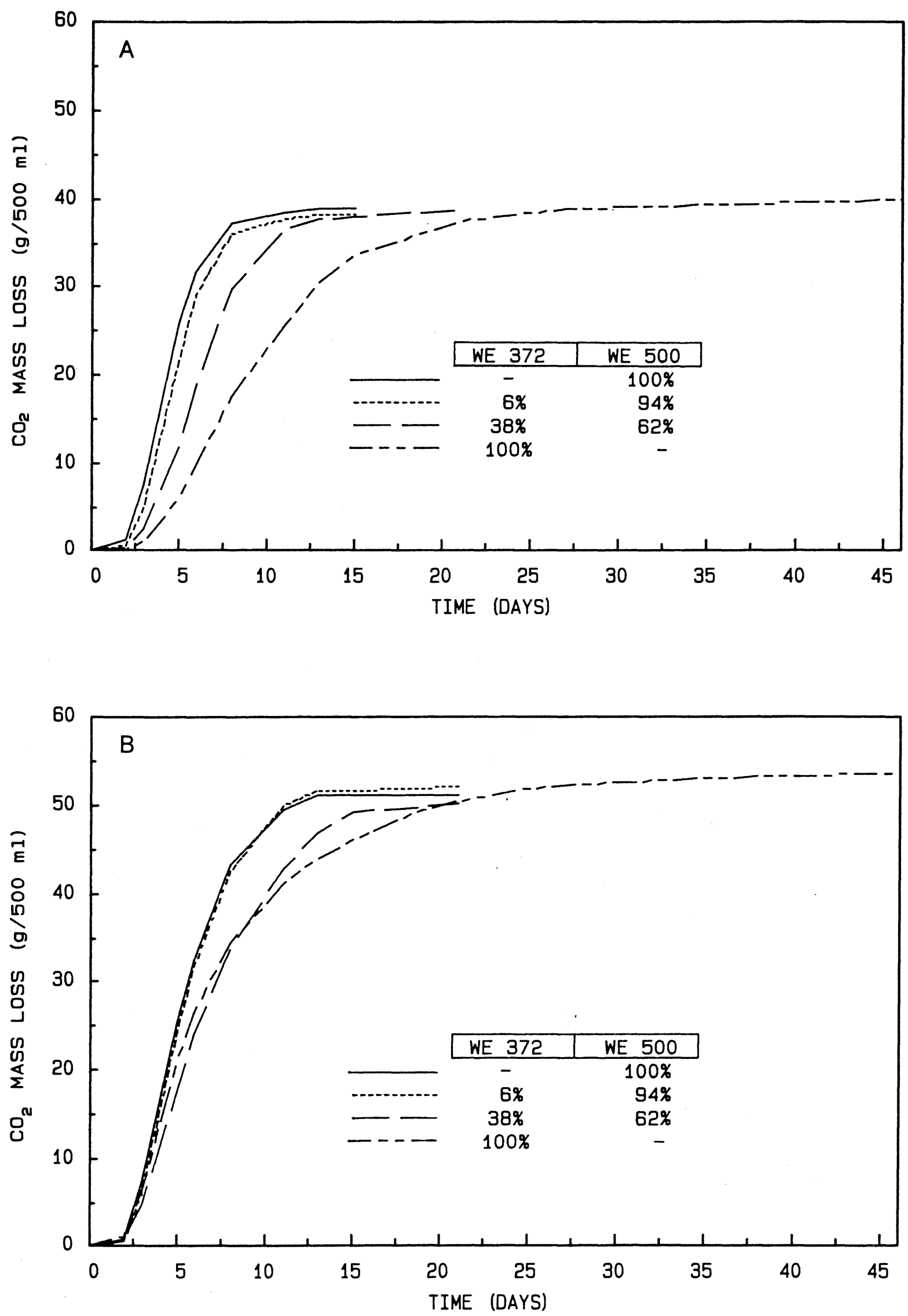

FIG. 3

Fermentation curves obtained in Riesling (A) and Vital (B) musts inoculated with varying concentrations of yeast strains WE 372 and WE 500 (VORI collection) at $15^{\circ} \mathrm{C}$. 


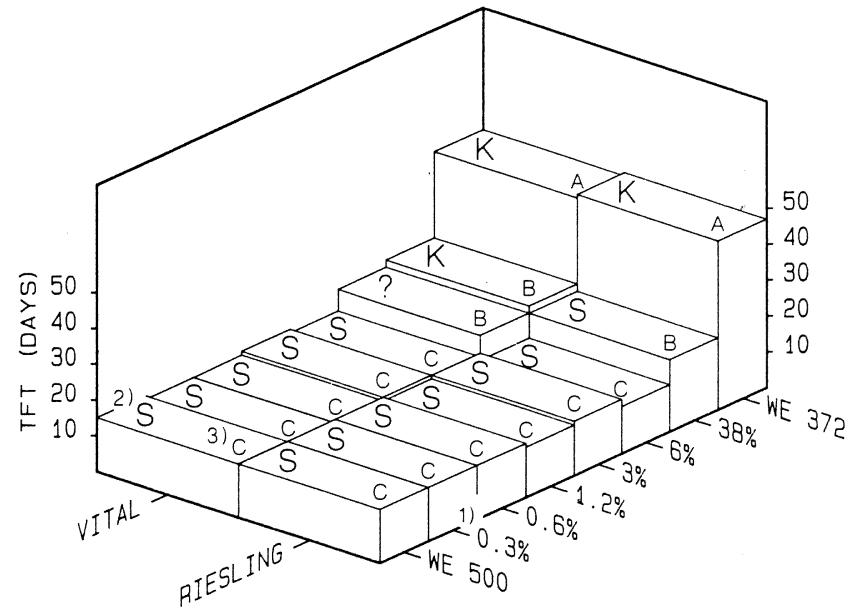

FIG. 4

Total fermentation time (TFT) for Riesling and Vital musts inoculated with varying concentrations of yeast strains WE 372 and WE 500 (VORI collection) along with the killer status of residual yeasts at the end of fermentation.

1) $0,3 \%$ to $38 \%$ are the ratios of WE 372 to WE 500 in the respective inocula.

2) $\mathrm{K}=$ killer and $\mathrm{S}=$ sensitive status of yeasts after fermentation. ? = result unknown.

3) A,B \& C denote groups which are significantly different (Scott \& Knott, 1974) for each cultivar separately.

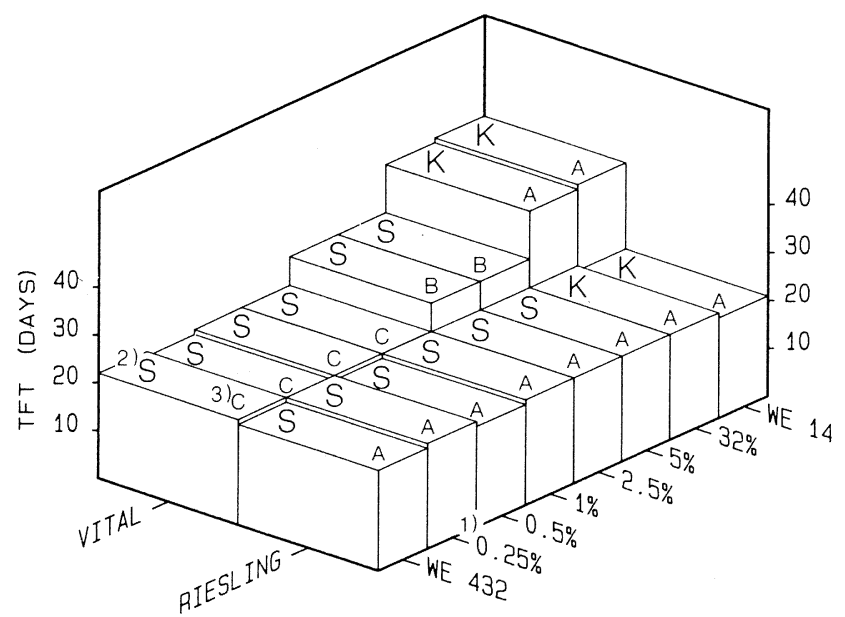

FIG. 5

Total fermentation time (TFT) for Riesling and Vital musts inoculated with varying concentrations of yeast strains WE 14 and WE 432 (VORI collection) along with the killer status of residual yeasts at the end of fermentation.

1) $0,25 \%$ to $32 \%$ are the ratios of WE 14 to WE 432 in the respective inocula at the start of fermentation.

2) $\mathrm{K}=$ killer and $\mathrm{S}=$ sensitive status of yeasts after fermentation.

3) A,B \& C denote groups which are significantly different (Scott \& Knott, 1974) for each cultivar separately.

than the yeast treatments themselves. This is borne out by the high correllation between TFT and VA $(r=0,86)$ and the fact that WE 500 usually yields wines with a higher VA than does WE 14 if fermentation proceeds under conditions conducive to fast fermentations (Tromp, 1984).

\section{CONCLUSIONS}

The high incidence of sensitive strains in the VORI culture collection is interesting as yeast strains selected for their oenological characteristics will thus in all probability be sensitive to killer toxin. Results of the $\mathrm{pH}$ study show that killer action should be non-existent at the $\mathrm{pH}$ of must. These results, however, were obtained by plating techniques on agar and do not correspond very well with results obtained with the fermentation studies. These latter studies show that if a killer strain is present at a concentration of approximately 2,5\% or less it will not take over or increase TFT. Even when the killer strain did in fact take over the fermentation, TFT was never increased to such an extent that it took longer than the killer on its own to complete fermentation. From the results of this study it seems that changes in TFT were caused by the inherent fermentative ability of the strain in a specific must rather than by its killer character.

In practice the fact that a yeast strain is either killer or sensitive should not at all exclude its use. Killer character must be a distinct advantage in a pure culture strain as this would ensure fermentation by this strain only (WE 14 and WE 372 are examples of such strains in use in the South African wine industry). Should a strain be sensitive (examples WE 432 and WE 500), take-over by killer strains can easily be avoided by simple cellar hygiene - a tank in which a killer strain was previously used has only to be rinsed before a sensitive strain is employed in a further fermentation. The natural flora present in must should furthermore not influence fermentation when inoculated with a sensitive strain because of the preponderance of the latter.

It is finally concluded that the use of a yeast strain should not hinge on whether it is a killer or sensitive, but rather on its oenological characteristics. Killer characters, however, should be known for a specific strain and kept in mind when it is used in practice.

\section{LITERATURE CITED}

ANONYMOUS, 1984. Utilization of dry yeast in winemaking. Lallemand Inc., Montreal, Canada.

BARRE, P., 1984. Le mécanisme Killer dans la concurrence entre souches de levures Evaluation et prise en compte. Bull. O.I.V. 57, 635-643.

BEVAN, E.A. \& MAKOWER, M., 1963. The physiological basis of the killer character in yeast. Proc. Int. Congr. Genet. 1, 202-203.

CIOLFI, G., 1985. Distribuzione dei fenotipi killer, neutro, sensibile nel corso di fermentazioni spontanee. Riv. Vitic. Enol. 38, 242-253.

CUINER, M.C. \& GROS, C., 1983. Enquete sur la repartition des levures "killer" en France. Vignes vins 318, 25-27.

HAMMOND, J.R.M. \& ECKERSLEY, K.W., 1984. Fermentation properties of brewing yeast with killer character. J. Inst. Brew. 90, $167-177$

HARA, S., IIMURA, Y. \& OTSUKA, K., 1980. Breeding of useful killer wine yeasts. Am. J. Enol. Vitic. 31, 28-33.

IMAMURA, T., KAWAMOTO, M. \& TAKOAKA, Y., 1974 Characteristics of a main mash infected by killer yeast in saké brewing and the nature of its killer factor. J. Ferment. Technol. 52, 293-299.

MAULE, A.P. \& THOMAS, P.D., 1973. Strains of yeast lethal to brewery yeasts. J. Inst. Brew. 79, 137-141.

PFEIFFER, P. \& RADLER, F., 1984. Comparison of the killer toxin of several yeasts and the purification of a toxin of type $\mathrm{K}_{2}$. Arch. Microbiol. 137, 357-361. 